\title{
Perceptual-motor abilities in pre-school preterm children
}

\author{
Paola De Rose ${ }^{\mathrm{a}, \mathrm{b}}$, Emilio Albamonte ${ }^{\mathrm{a}}$, Valentina Laganà a , Serena Sivo ${ }^{\mathrm{a}}$, Silvia Pisoni ${ }^{\mathrm{c}}$, Francesca Gallini ${ }^{\mathrm{d}}$, \\ Francesca Serrao ${ }^{d}$, Francesca Tinelli ${ }^{e}$, Giulia Purpura ${ }^{\mathrm{e}}$, Alessandra Ometto ${ }^{\mathrm{c}}$, Annalisa Sacco ${ }^{\mathrm{a}}$, \\ Michela Quintiliani ${ }^{\text {a }}$, Valentina De Clemente ${ }^{\mathrm{a}}$, Alessandra Graziano ${ }^{\mathrm{a}}$, Domenico M. Romeo ${ }^{\mathrm{a}}$, \\ Simona Frezza ${ }^{\mathrm{d}}$, Patrizia Papacci ${ }^{\mathrm{d}}$, Fabio Mosca ${ }^{\mathrm{e}}$, Stefano Vicari ${ }^{\mathrm{b}}$, Luca A. Ramenghi ${ }^{\mathrm{c}, \mathrm{f}}$, Giovanni Cioni ${ }^{\mathrm{e}}$, \\ Costantino Romagnoli ${ }^{a}$, Eugenio Mercuri ${ }^{a}$, Daniela Ricci ${ }^{\mathrm{a}, *}$ \\ a Department of Paediatric Neurology, Catholic University, Rome, Italy \\ b Child Neuropsychiatry Unit, Department of Neuroscience, Bambino Gesù Children's Hospital, IRCCS, Rome Italy \\ c Neonatal Intensive Care Unit, Fondazione IRCCS Ca' Granda-Ospedale Maggiore Policlinico Milano, Milan Italy \\ d Division of Neonatology Catholic University of Sacred Heart, Rome Italy \\ e Stella Maris Scientific Institute, Pisaltaly \\ ${ }^{\mathrm{f}}$ Neonatal Intensive Care Unit, Gaslini Children's Hospital, Genoa Italy
}

\section{A R T I C L E I N F O}

\section{Article history:}

Received 8 January 2013

Received in revised form 19 June 2013

Accepted 1 July 2013

Available online $\mathrm{xxxx}$

\section{Keywords:}

Preterm infants

Perceptual-motor

Outcome

\begin{abstract}
A B S T R A C T
Background: Several studies report a high percentage of premature infants presenting perceptual motor difficulties at school age. The new version of the Movement Assessment Battery for Children allows the assessment of perceptual-motor abilities in children from the age of 3 years.

Aims: To evaluate early perceptual-motor abilities in prematurely born children below the age of 4 years. Study design: The Movement Assessment Battery for Children 2nd edition was administered to 105 low-risk prematurely born children ( $<32$ weeks gestation) and in a control group of 105 term-born children matched for age and sex. All children were assessed between the age of 3 years and 3 years- 11 months.

Results: 63 children (60\%) had total scores above the 15th percentile, $15(14.3 \%)$ had scores between the 5th and the 15 th percentile, and 13 (12.4\%) below the 5th percentile. The remaining 14 children $(13.3 \%)$ refused to perform or to complete the test. The difference between preterm and control group was significant for total scores, Manual Dexterity and Aiming and Catching scores. In the preterm group there was a correlation between age at testing, total scores and Aiming and Catching subscores. The Movement ABC-2 subscores were significantly lower in children born below 29 weeks.

Conclusion: Perceptual-motor difficulties can already be detected on the assessment performed before the age of 4 years. Prematurely born children assessed between 3 years and 3 years -3 months appeared to have more difficulties in performing the test than the older ones or their age matched term-born peers. These findings support the possibility of a delayed maturation in the younger age group.
\end{abstract}

(c) 2013 Elsevier Ireland Ltd. All rights reserved.

\section{Introduction}

Several follow up studies of prematurely born children have previously reported perceptual-motor difficulties at school age [1-6]. The majority of these studies using the Movement Assessment Battery for Children, a test assessing manual dexterity, ball games and static and dynamic balance [1-6], showed that up to $60 \%$ of children born below the gestational age of 35 weeks had difficulties at school age.

\footnotetext{
* Corresponding author at: Pediatric Neurology Unit, Gemelli Hospital, Largo Gemelli, 8 - 00168 Rome, Italy. Tel.: + 3906 30155340; fax: + 390630154363.

E-mail address: dricciola@gmail.com (D. Ricci).
}

No systematic study has so far been performed to identify earlier signs of perceptual-motor difficulties. While several papers have reported early neurodevelopmental findings using general scales or have explored specific aspects of neurodevelopment, such as visual motor, sustained attention, memory and language production below the age of 4 years [7-10], less has been reported on early perceptual-motor abilities. One of the reasons is that the original version of the Movement $A B C$ [11], or its previous version, the Test of Motor Impairment, were developed for children above the age of 4 years [1-4]. The Movement ABC 2nd edition can be used in children as young as 3 years [12] and can therefore allow detection of earlier perceptual-motor difficulties. The test has recently been shown to be a reliable measure in a group of 3 year old children [13] and in 6 to 12 year old Taiwanese children with Developmental Coordination Disorder [14]. 
The aim of this study was to evaluate possible signs of perceptualmotor difficulties in a cohort of low-risk children born prematurely assessed before the age of 4 years.

\section{Methods}

Study cohort: prematurely born children followed at the neonatal intensive care unit at Gemelli Hospital, Rome, Mangiagalli Hospital, Milan, and Stella Maris Institute, Pisa were assessed between February 2009 to May 2011.

Children were consecutively enrolled if:

a) they were born between 25 and 32 weeks gestational age (GA) determined from first trimester ultrasound scans;

b) cranial ultrasound scans were normal or only showed transient flares or germinal layer haemorrhages during the first 2 postnatal weeks and, at term equivalent age, showed no parenchymal abnormality and no evidence of atrophy i.e. no dilated ventricles $(>14 \mathrm{~mm}$ Ventricular Index (VI)), irregular ventricular margins, widened interhemispheric fissure or enlarged extracerebral space [15];

c) they were clinically stable by 35 weeks.

We excluded children with major congenital malformations, genetic chromosomal abnormalities, metabolic disorders, congenital infection or any sign of encephalopathy or seizures during their neonatal course, severe jaundice requiring phototherapy, and retinopathy of prematurity greater than stage 2 .

In all, developmental quotient (DQ) at 2 years was evaluated with the Griffiths Mental Development Scales and neurological examination had been reported as normal at the age of 2 years.

All prematurely born children were assessed using chronological age and not corrected age as in our routine we use corrected age up to the age of two years.

Control group: we also assessed a control group of term born children ( $G A \geq 37$ weeks), matched for age and sex. All had a negative clinical history for neurological diseases. The control group was recruited from three primary schools in Rome and Pisa.

This study was approved by the Ethical Committee in each of the three Centers involved in the research. Parents of children in the preterm and in the control group gave informed consent to the work.

\subsection{Perceptual motor abilities}

These were evaluated by using the Test component of the Movement $\mathrm{ABC}-2$. The test includes three items assessing manual dexterity, two assessing aiming and catching and three balance.

Individual results can be compared and scored according to normative data available for each year and, within each year, for the first and the second semester (i.e. 3 years to 3 years -5 months and 3 years6 months to 3 years-11 months). The test is designed to give a global score but the subscores for the three subscales can also be compared to age specific normative data.

All assessments were administrated by pediatric neurologists.

The results were scored in two ways:

First, we compared the scores of the prematurely born children with the normative data available from the manual. The results were scored as normal (when falling above the $15^{\text {th }}$ centile), borderline (when falling below the $15^{\text {th }}$ centile but above the $5^{\text {th }}$ ) and abnormal (when falling below the $5^{\text {th }}$ centile). We also noted if the child refused to perform the test or part of it.

As the Movement ABC-2 has not yet been validated in Italy, the results were also compared with a control group of preschool children matched for age and sex.

ANOVA model was used to compare differences in the Movement $\mathrm{ABC}-2$ results between prematurely born children and the control group. In prematurely born children the correlation between the
Table 1

Movement ABC-2 percentile scores in prematurely born children and in control group.

\begin{tabular}{lllllll}
\hline & \multicolumn{2}{l}{$\begin{array}{l}\text { Prematurely born } \\
\text { children }\end{array}$} & & \multicolumn{2}{l}{ Control group } & \\
\cline { 2 - 3 } MABC-2 & Median & Range & & Median & Range n & p value \\
Percentile Score & & & & & \\
\hline Total & 32.76 & $0.5-99$ & 52.17 & $2-100$ & $\mathrm{p}<0.00001$ \\
Manual dexterity & 30.16 & $0.5-98$ & 58.65 & $5-100$ & $\mathrm{p}=0.00002$ \\
Aiming and catching & 32.95 & $1-99$ & & 45.17 & $0-100$ & $\mathrm{p}=0.0276$ \\
Balance & 41.30 & $0.5-99$ & & 48.56 & $0-100$ & $\mathrm{p}=0.343323$ \\
Refusal & 14 & & 1 & & $\mathrm{p}<0.00001$ \\
\hline
\end{tabular}

Movement $\mathrm{ABC}-2$, age at testing time, gestational age and birth weight were also investigated using the Pearson correlation analysis.

Differences between groups were considered significant after correction for multiple comparisons (P corrected $<0.05$ ).

Post-hoc analyses was conducted to qualify the nature of interaction (Tukey's Honest Significance Test), between subgroups of sampled populations.

\section{Results}

One hundred and five prematurely born children (43 males, 62 females) fulfilled the inclusion criteria and all agreed to participate to the study. Median gestational age at birth was 29.2 weeks, range 26-31 weeks. Median birth-weight was 1177 grams, range 480-2200 grams. Median chronological age at the assessment was 40.33 months, range 36-47 months.

All had normal DQ at 2 years and none had signs of cerebral palsy on neurological examination.

\subsection{Movement $A B C-2$}

When compared to the available normative data, 63 of the 105 prematurely born children $(60 \%)$ had total scores at or above the $15^{\text {th }}$ percentile. Fifteen of the remaining 42 had scores below the $15^{\text {th }}$ but above the $5^{\text {th }}$ centile $(14.3 \%)$ and 27 (25.8\%) had scores below the $5^{\text {th }}$ percentile. While 13 of these $27(12.4 \%)$ completed the test with abnormal scores (below the $5^{\text {th }}$ ) the other 14 (13.3\%) refused to perform or to complete the test. The results of these children, according to the manual, had also to be considered below the $5^{\text {th }}$ centile, but were kept separately.

Nineteen of the 63 children with total scores above the $15^{\text {th }}$ percentile had a score below the $15^{\text {th }}$ percentile on one of the sub-sections. Details of standard scores and centiles are provided in Tables 1 and 2.

\subsubsection{Control group}

When compared to the normative data, available from the manual, 99 of the 105 children (94.2\%) had total scores at or above the $15^{\text {th }}$ percentile. Six children (5.7\%) had total scores below the $15^{\text {th }}$ percentile, of which $1(0.9 \%)$ fell below the $5^{\text {th }}$ percentile. Twenty children had total scores above the $15^{\text {th }}$ percentile but had a score at or below the $15^{\text {th }}$

Table 2

Movement ABC-2 standard scores in prematurely born children and in control group.

\begin{tabular}{|c|c|c|c|c|}
\hline \multirow[b]{2}{*}{ MABC-2 Standard Score } & \multicolumn{2}{|c|}{$\begin{array}{l}\text { Prematurely born } \\
\text { children }\end{array}$} & \multicolumn{2}{|c|}{ Control group } \\
\hline & Median & SD & Median & SD \\
\hline Total & 7.11 & 3.74 & 10 & 3.14 \\
\hline Manual dexterity & 7.24 & 3.42 & 10.99 & 2.97 \\
\hline Aiming and catching & 7.58 & 3.52 & 9.57 & 3.11 \\
\hline Balance & 8.17 & 4.4 & 9.97 & 3.35 \\
\hline
\end{tabular}




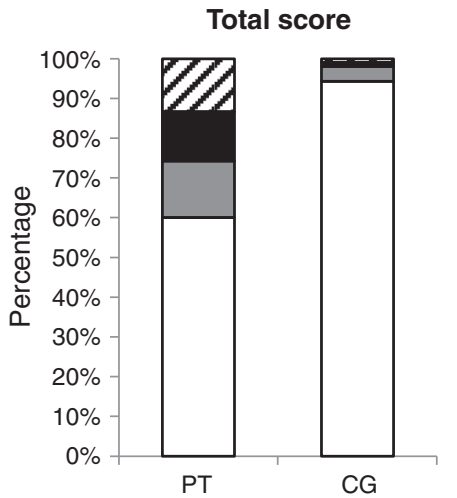

Aiming and Catching

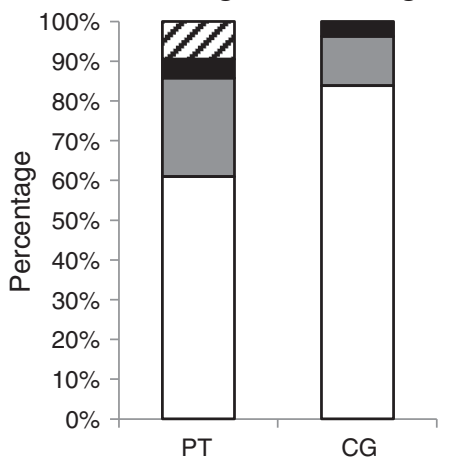

Manual Dexterity

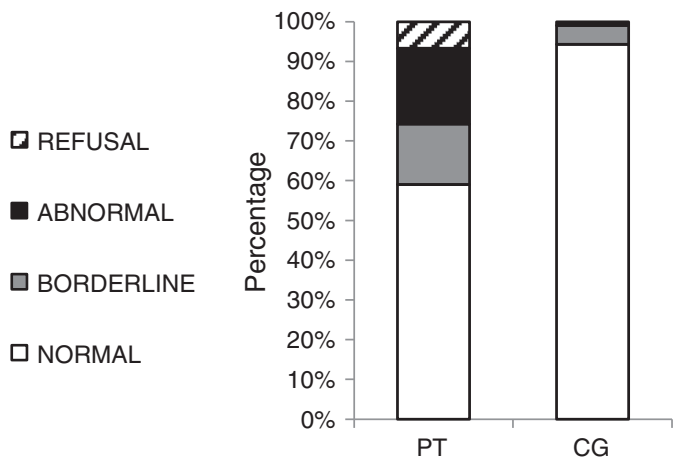

D REFUSAL

- ABNORMAL

口 BORDERLINE

$\square$ NORMAL

Fig. 1. Movement ABC-2 total and subscores in prematurely born children (PT) and control group (CG).
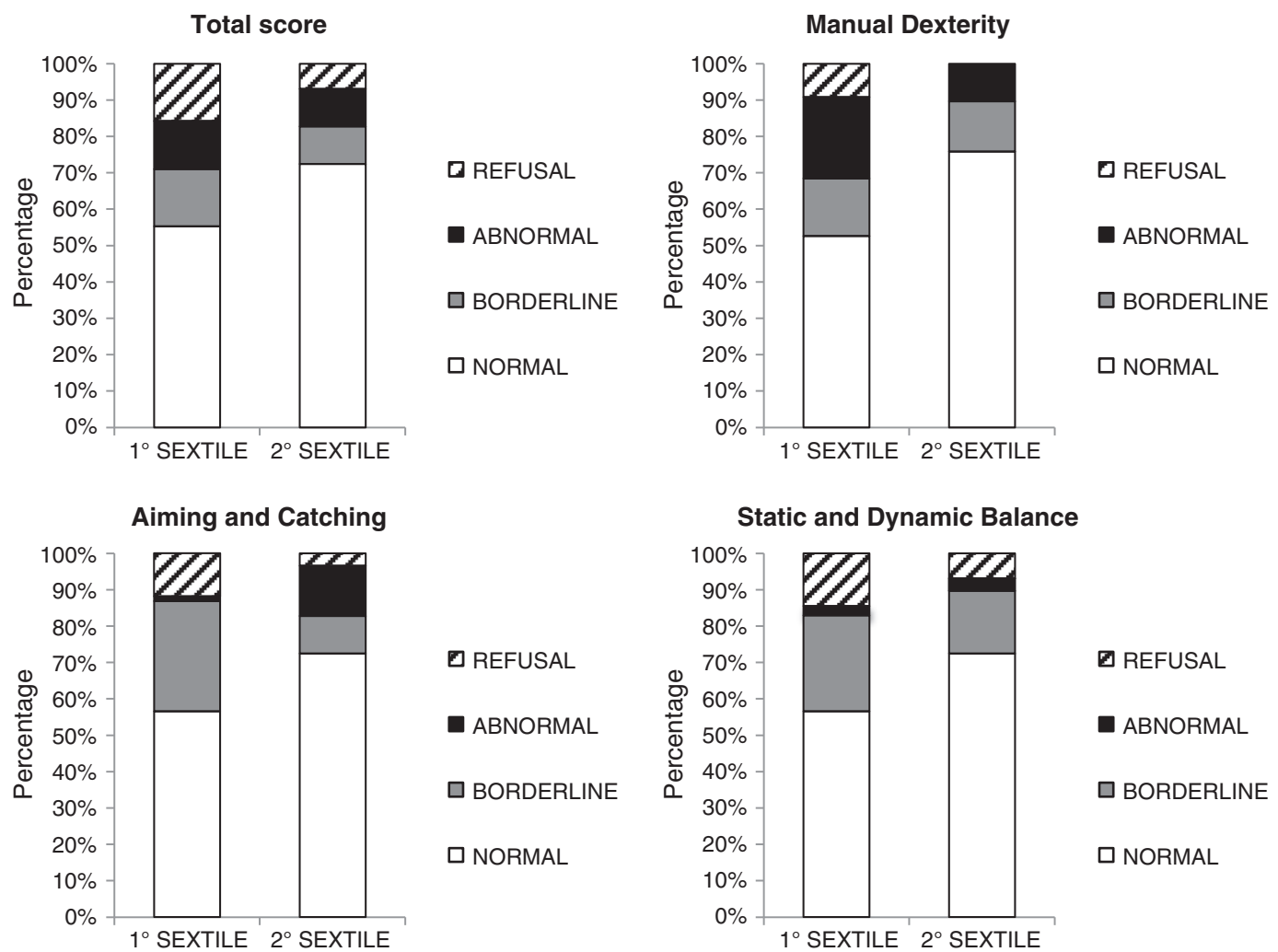

Fig. 2. Movement ABC-2 total and subscores according to the age at the test in prematurely born children. 
percentile on one of the sub-sections. Details are provided in Table 1 and Fig. 1.

\subsection{Comparison between study and control group}

There was a difference in the Movement ABC-2 total scores between prematurely born children and control group $(F(1,194)=24.53$, $\mathrm{p}<0.001$ ) with prematurely born children having lower scores (mean $(\mathrm{M})=32.76$, Standard Error $(\mathrm{SE})=2.85$; control group: mean $(\mathrm{M})=$ $52.17 \mathrm{SE}=2.69)$ with a group effect $\mathrm{F}(1,194)=29.98, \mathrm{p}<0.001$ and a subscore effect $F(2,388)=10.77 \mathrm{p}<0.001$.

There was also a difference between prematurely born children and the control group in manual dexterity (prematurely born children: $\mathrm{M}=30.16$ vs control group: $\mathrm{M}=58.65), \mathrm{p}<0.001$ and in aiming and catching scores (prematurely born children: $\mathrm{M}=32.95$ vs control group: $\mathrm{M}=45.17), \mathrm{p}=0.02$, but not in balance scores $(\mathrm{p}=0.34$ ) (Tables 1-2).

\subsubsection{Movement $A B C-2$ and age at testing}

Fig. 2 shows the distribution of percentage of normal and abnormal results according to the age when the test was performed with a higher incidence of refusals and abnormal results in the children assessed before 3 years -6 months compared to the older ones. Eleven of the 14 children who refused to complete the test were between 3 years and 3 years -3 months.
A significant age effect on the Movement ABC-2 scores $F(4,86)=2.7$, $\mathrm{p}=0.03$ was found in the prematurely born group but not in the control group $\mathrm{F}(3,87)=2.1520, \mathrm{p}=0.09$.

The prematurely born group assessed before 3 years -6 months showed lower scores than those assessed at an older age in the Movement $\mathrm{ABC}-2$ total scores $(\mathrm{M}=29.12$ vs 38.46), $\mathrm{p}=0.04(\mathrm{r}=0.21)$ and in aiming and catching subscores ( $\mathrm{M}=36.63$ vs 48.53$), \mathrm{p}=$ $0.01(r=0.24)$.

\subsubsection{Movement $A B C-2$ and $G A$ at birth}

When the prematurely born group was subdivided according to $\mathrm{GA}$, there were some differences in Movement ABC-2 subscores $\mathrm{F}(8$, 170 ) $=2.27, \mathrm{p}=0.02$ (Fig. 3). Children born at 26-28 weeks GA or below had significantly lower performances compared to those born at higher GA, in particular to those of 31-32 weeks in the Movement ABC-2 total scores ( $M=12$ vs 43.4), $\mathrm{p}=0.01$ and in manual dexterity subscores ( $M=13.5$ vs 43.4 ), $\mathrm{p}=0.01$. There were no differences in the children born at other gestational ages.

\subsubsection{Movement $A B C-2$ and birth weight}

The prematurely born children with a birth weight below $1000 \mathrm{~g}$ did not differ from those with a birth weight $>1000 \mathrm{~g}$ on all the Movement ABC-2 subscores $\mathrm{F}(12,222)=1.53, \mathrm{p}=0.11$ (Fig. 4).

\subsubsection{Movement $A B C-2$ and cranial ultrasound}

There was no difference in scores between children with normal and those who had minimal lesions on neonatal ultrasound.

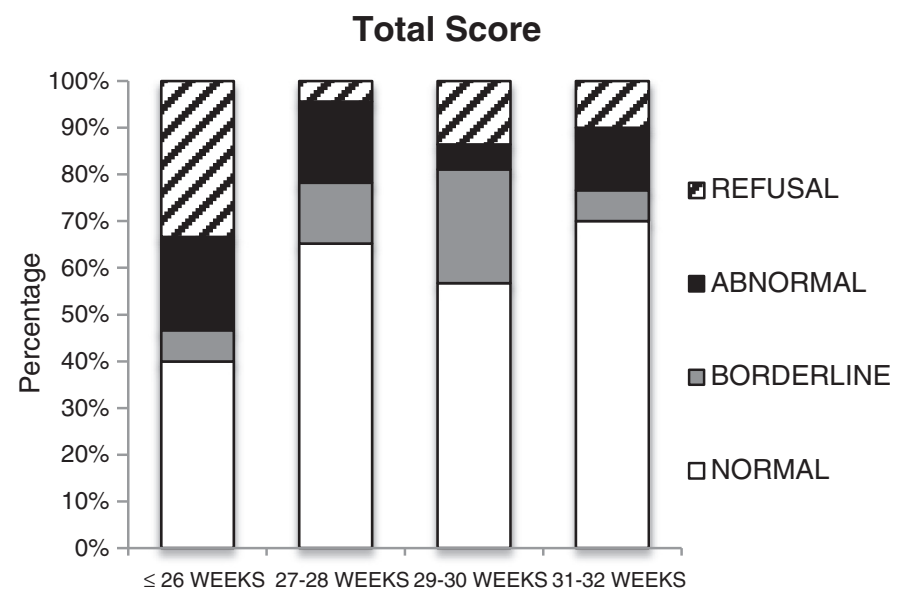

Aiming and Catching

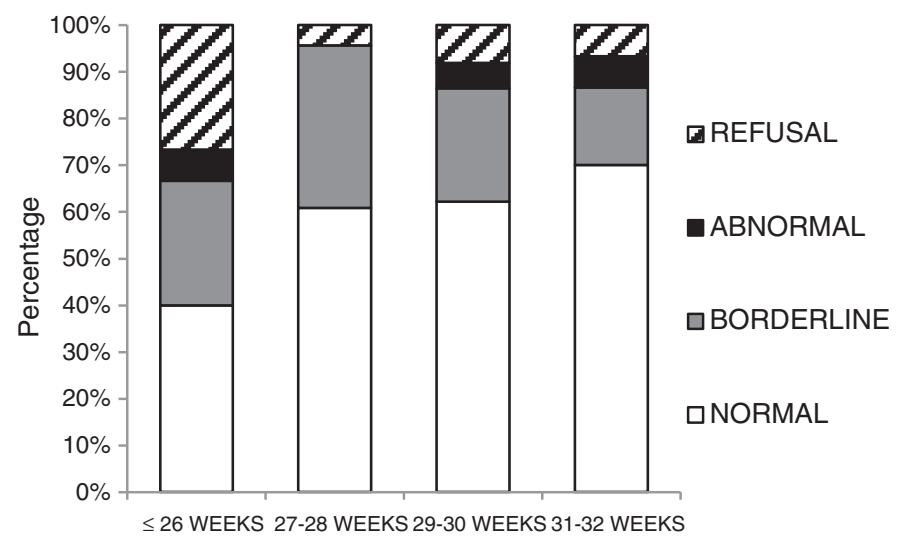

Manual Dexterity

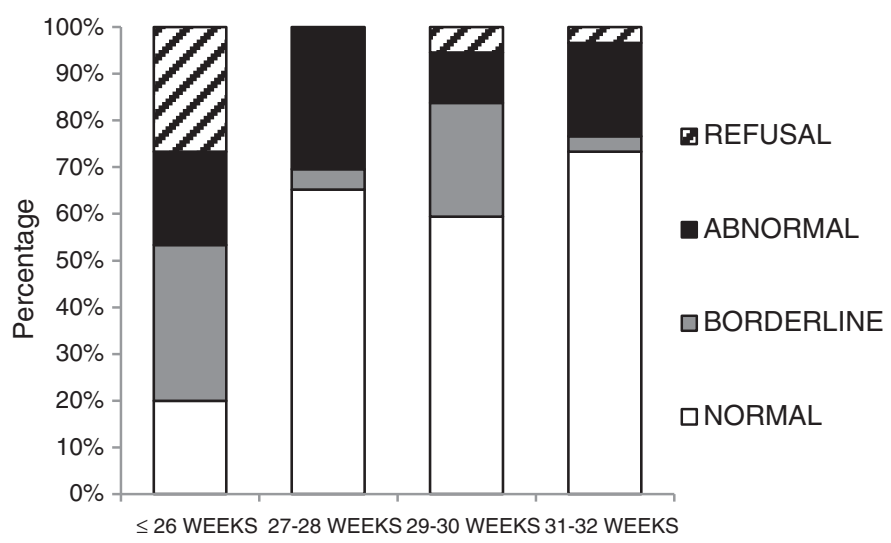

Static and Dynamic Balance

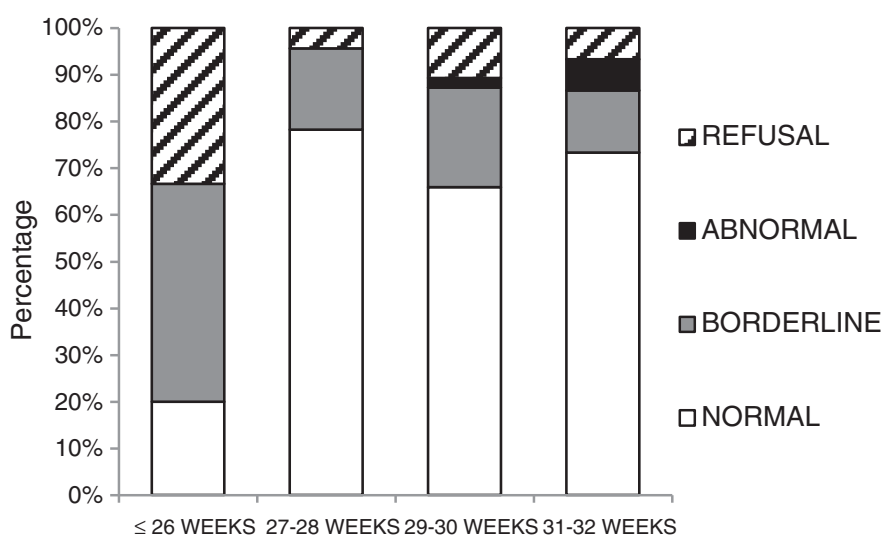

Fig. 3. Movement $\mathrm{ABC}-2$ total and subscores according to gestational age at birth in prematurely born children. 
Total score

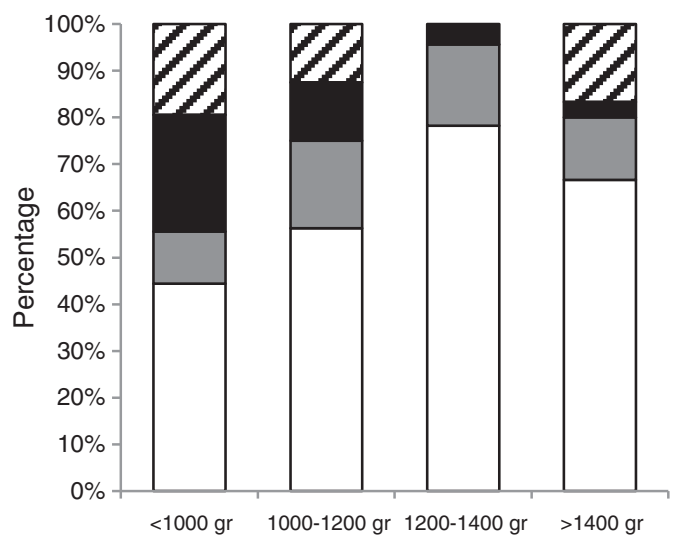

Aiming and Catching

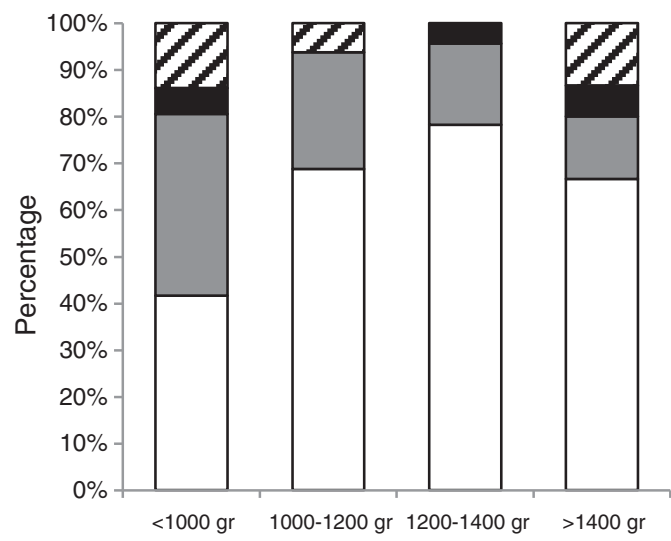

REFUSAL

- ABNORMAL

口BORDERLINE

口NORMAL

๑REFUSAL

ABNORMAL

口BORDERLINE

口NORMAL

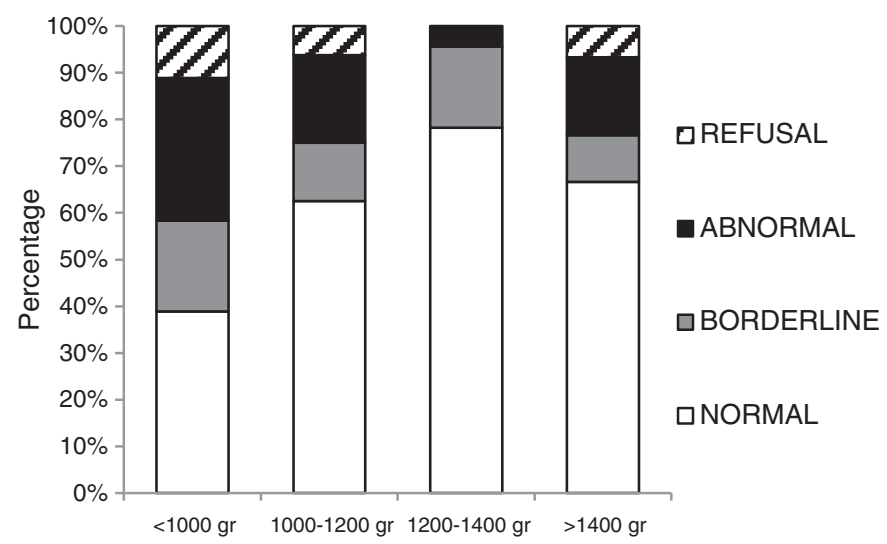

Static and Dynamic Balance

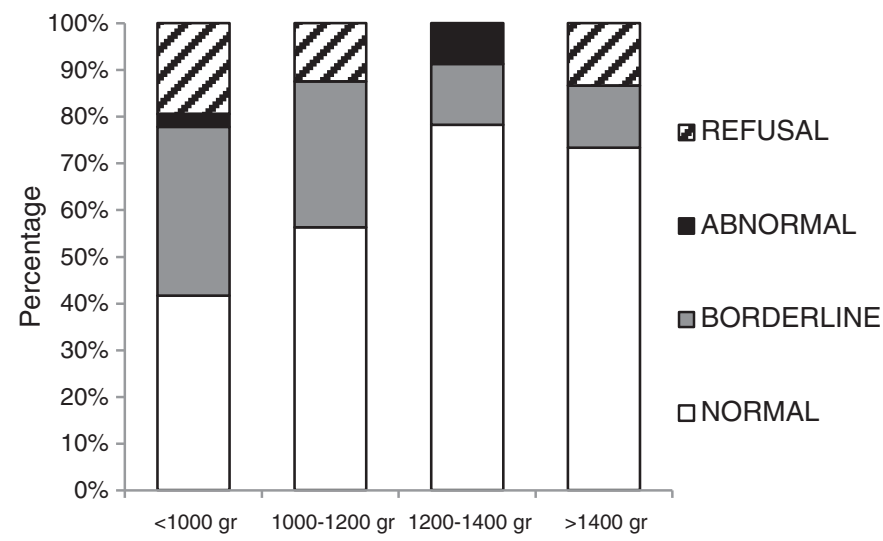

Fig. 4. Movement ABC-2 total and subscores according to the birth weight in prematurely born children.

\section{Discussion}

Using the Movement ABC-2 $2^{\text {nd }}$ edition we were able to assess a cohort of prematurely born children before the age of 4 years. Our results showed that 15 of the 105 prematurely born children (14.3\%) had scores between the $5^{\text {th }}$ and the $15^{\text {th }}$ centile and another 13 below the $5^{\text {th }}(12.4)$ with an additional 14 children (13.3\%) refusing to perform or to complete the test. According to manual instructions the results of these children should be scored as failed and therefore below the $5^{\text {th }}$ centile. The percentage of abnormal results therefore rises to $40 \%$ when we also included the children who refused to perform or complete the battery.

These results are not easily comparable with previous studies in older children as in the other papers there are no details of children scored as abnormal because of a refusal to perform or to complete the test.

It is of interest that the refusal to complete the test mainly occurred in the youngest children, i.e. those assessed between 3 years and 3 years -3 months and this was more obvious on the items testing manual dexterity. There was an obvious age effect with children examined below the age of 3 years -6 months not only having the largest number of refusals to complete the assessment but also worse results in the overall score, in manual skills and in aiming and catching. Poorer performance was often related to a poor concept of timing and attention. A few children were able to perform the task, but required more time than controls to complete them, with a short attention span and tendency to get distracted during the task. This was not observed in the age matched control group. Our findings suggest that early in the third year of life prematurely born children may have a delay in the maturation of attention or in the control of hyperactive behaviour. As in our cohort attention difficulties and poor cooperation were less obvious in children assessed after the age of 3 years- 3 months, it appears that these abilities may progressively improve during the third year of life. Not surprisingly, the refusals were more frequent in the children born below 28 weeks GA ( 6 out of $23,26 \%$ ) but could also be observed in those born after 28 weeks GA ( 8 out of $82,9.7 \%$ ). More generally, children born below 28 weeks GA had significantly lower performance compared to those born after 28 weeks. In contrast, although children born with a weight below $1000 \mathrm{~g}$ had lower performances compared to those with a weight above $1000 \mathrm{~g}$, the difference was not significant.

Because the Movement ABC-2 has not been yet validated in the Italian population, in order to exclude possible cultural differences, we also assessed a control group matched for age and sex. Only one of the 105 controls refused to complete the assessment. Not surprisingly the control group had a significantly better performance compared to the study group.

The results in the control group showed that there are no large differences between our Italian control group and the UK norms [12]. Two children $(1.9 \%)$ in the control group had results below the $5^{\text {th }}$ centile and 4 (3.8\%) had scores between the $5^{\text {th }}$ and the $15^{\text {th }}$ centile. Further normative data are being systematically collected to obtain more accurate information on the frequency distribution of the results for each item in a larger sample of the Italian population. 
Our findings raise the question of whether corrected age should have been used instead of chronological age. There is currently no consensus regarding when to stop correcting age for prematurity. The majority of the studies on preterm children correct through age two years but other studies correct for the first three years [16,17]. In our study the youngest group, assessed below 3 years -3 months chronological age and therefore below the age of 3 years corrected age, appeared to have more difficulties in completing the tasks in the time frame allowed. These findings appear to suggest a possible delay in maturation of these aspects and the need to use corrected age but, as the numbers were relatively small, one cannot exclude that the refusal to complete the assessments observed in the younger children may be an early marker of attention difficulties that are frequently detected in prematurely born children at school age [18-20]. As all the children in this study will be reassessed after one year and again at school age, when more specific assessment of attention can be performed, this will help to establish the possible prognostic value of these early findings.

It is of interest that the incidence of perceptual-motor difficulties in our cohort was still slightly lower than that reported in previous studies assessing prematurely born children at school age $[1,4,6]$. Further follow up in our cohort will also help to establish whether the early assessment at 3 years fails to detect abnormalities that may become obvious at a later age.

\section{Conflict of interest statement}

Authors have nothing to disclose.

\section{References}

[1] Jongmans M, Mercuri E, de Vries L, Dubowitz L, Henderson SE. Minor neurological signs and perceptual-motor difficulties in prematurely born children. Arch Dis Child Fetal Neonatal Ed 1997;76:F9-F14.

[2] Atkinson J, Braddick O. Visual and visuocognitive development in children born very prematurely. Prog Brain Res 2007;164:123-49.

[3] Roberts G, Anderson PJ, Davis N, De Luca C, Cheong J, Doyle LW. Developmental coordination disorder in geographic cohorts of 8-year-old children born extremely preterm or extremely low birth weight in the 1990s. Dev Med Child Neurol 2011;53: $55-60$.

[4] Marlow N, Hennessy EM, Bracewell MA, Wolke D. EPICure Study Group. Motor and Executive Function at 6 Years of Age After Extremely Preterm Birth. Pediatrics 2007:120:793-804

[5] de Kieviet JF, Piek JP, Aarnoudse-Moens CS, Oosterlaan J. Motor development in very preterm and very low-birth-weight children from birth to adolescence: a meta-analysis. JAMA 2009;302:2235-42.

[6] Goyen TA, Lui K. Developmental coordination disorder in "apparently normal" school children born extremely preterm. Arch Dis Child 2009;94:298-302.

[7] Vicari S, Caravale B, Carlesimo GA, Casadei AM, Allemand F. Spatial working memory deficits in children at age 3-4 who were low birth weight, preterm infants. Neuropsychology 2004;18:673-8.

[8] Caravale B, Tozzi C, Albino G, Vicari S. Cognitive development in low risk preterm infants at 3-4 years of life. Arch Dis Child Fetal Neonatal Ed 2005;90:F474-9.

[9] Caravale B, Mirante N, Vagnoni C, Vicari S. Change in cognitive abilities over time during preschool age in low risk preterm children. Early Hum Dev Published Online First 1 November 2011; 2011. http://dx.doi.org/10.1016/j.earlhumdev.2011.09.011.

[10] Marlow N. Neurocognitive outcome after very preterm birth. Review. Arch Dis Child Fetal Neonatal Ed 2004;89:F224-8.

[11] Henderson S, Sugden D. The movement assessment battery for children. London, UK: The Psychological Corporation; 1992.

[12] Henderson SE, Sugden DA, Barnett AL. Movement assessment battery for children-2 second edition [Movement ABC-2]. London, UK: The Psychological Corporation; 2007.

[13] Smits-Engelsman BC, Niemeijer AS, van Waelvelde H. Is the Movement Assessment Battery for Children-2nd edition a reliable instrument to measure motor performance in 3 year old children? Res Dev Disabil 2011;32:1370-7.

[14] Wuang YP, Su JH, Su CY. Reliability and responsiveness of the Movement Assessment Battery for Children-Second Edition Test in children with developmental coordination disorder. Dev Med Child Neurol 2012;54:160-5.

[15] Levene MI. Measurement of the growth of the lateral ventricles in preterm infants with realtime ultrasound. Arch Dis Child 1981:56:900-4.

[16] Ment LR, Vohr B, Oh W, Scott DT, Allan WC, Westerveld M, et al. Neurodevelopmenta outcome at 36 months' corrected age of preterm infants in the Multicenter Indomethacin Intraventricular Hemorrhage Prevention Trial. Pediatrics 1996:98:714-8.

[17] Houtzager BA, Gorter-Overdiek B, Van Sonderen L, Tamminga P, Van Wassenaer AG. Improvement of developmental outcome between 24 and 36 months corrected age in very preterm infants. Acta Paediatr 2010;99(12):1801-6.

[18] Mulder H, Pitchford NJ, Hagger MS, Marlow N. Development of executive function and attention in preterm children: a systematic review. Dev Neuropsychol 2009;34: 393-421.

[19] Aarnoudse-Moens CSH, Weisglas-Kuperus N, Duivenvoorden HJ, van Goudoever $\mathrm{JB}$, Oosterlaan J. Executive function and IQ predict mathematical and attention problems in very preterm children. PLoS One 2013;8(2):e55994.

[20] de Kieviet JF, van Elburg RM, Lafeber HN, Oosterlaan J. Attention problems of very preterm children compared with age-matched term controls at school-age. J Pediatr 2012;161(5):824-9. 